\title{
Research on Legal Issue of Copyright Protection in the Internet
}

\author{
Lijie Ai
}

School of Arts and Law, Wuhan University of Technology, Wuhan, Hubei, China, 430070

ljie9@163.com

Key words: legal issue, copyright protection, internet

\begin{abstract}
Nowadays, traditional system of copyright that mainly aims at protecting personal rights is facing challenges from the network serving for the public. This paper discusses the challenges of copyright protection in the internet, points out the items of copyright which needs the legal protection in the internet, and finally gives the measures to improve legal protection of copyright in the internet in order to provide references to the related researchers.
\end{abstract}

\section{Challenges of Copyright Protection in the Internet}

Since the emergence of network technology, the legal protection of copyright has become a big problem. It is easy and inexpensive to copy and spread a large range of work after the digital works. When you read a story on the Internet, want to copy it a give a person, or by mailing list gave a group of people reading this seemingly innocuous. However, as long as you knock a few more keyboards, you can give this article to the world over thousands of people. In today's non rational Internet economy, the move almost does not have to spend a penny. No one is very clear on the Internet who wants to pay, why pay, but for most users, it seems to be free of charge. This fee will not be the same as the ordinary postage rates, because the standard is built on the basis of the delivery of the goods. Under the premise of zero transaction costs, once the property is clearly defined, the allocation of resources is efficient. And it is because of the existence of transaction costs, making the protection of online copyright enforcement difficult. In theory, even though the online works have a strong public and non exclusive, the use of large numbers of people, but as long as the copyright owner to master the most advanced network tracking technology, and try to search the Internet illegal copy and use behavior, you can master a large number of illegal facts, so as to prosecute and get compensation. But the actual situation is that when online works spread wide enough, use sufficient numbers, the copyright owner must be paid search, signing and supervision costs than benefits thus obtained. Copyright people maintaining their rights are pyrrhic, online copyright assignment is invalid. How to solve the problem of copyright protection causes by the characteristics of the network itself has become a hot issue in the field of intellectual property. This paper agrees with the new rights of copyright protection, which is a problem that deserves to be discussed, and that the public interest should not be ignored at any time.

\section{Items of Legal Protection of Copyright in the Internet}

\section{Legal Protection of Network Transmission}

Copyright law takes a summary and list patterns in the use of copyright in China. Although not explicitly including the use of the Internet, but does not mean that the use of the Internet does not belong to the scope of copyright law. If people use copyright works cannot control the Internet, copyright will be useless in the network environment. The use of other people's works, but also the use of the work of one of the ways, should be the consent of the copyright owner. The challenge to copyright system has just begun, in the network technology today, it will not be predicted that it will give the copyright system, if there is a new situation, a new, with the technical characteristics of the exclusive right, then, in response to new technology, will always be in a passive state, in dealing with new types of disputes, but also because of the law and cannot start. However, such provisions are conducive to maintaining the continuity of the law, the formation of a legal tradition 
of copyright law, including the right to copy, issue, play, exhibition, etc.. It's reasonable to create a new right named network transmission copyright.

\section{Legal Protection of Technical Measures}

Digital technology makes the work of the reproduction of the work cheap, simple and fast. Anyone can achieve the high quality of the digital works, numerous restrictions on the copy, which greatly stimulated the production of illegal piracy. At the same time, due to the infringement of the copyright of the digital works is more subtle, and the network environment and the result of the infringement of the rapid spread of the world wide, the copyright owner is often difficult to remedy by legal means after the event. And in the face of a large number of the lack of economic compensation capacity of the end user, one by one to find and pursue its tort liability is clearly not realistic. In the Internet age, it is very difficult to protect the interests of the copyright owner. How to protect the interests of copyright holders and other intellectual property rights in the information age has become a difficult and hot issue in the field of intellectual property. With the use of technical means to carry out the tort law is becoming increasingly serious, many of the copyright owners have begun to use a variety of technical means to protect their rights in the digital works and the network. Development of technical protection measures to today, tens of thousands of its morphology and in the continuous innovation, even outstanding professionals may not exhaustively master. However, technical protection measures as a protective measures to protect the rights of the copyright owner.If it is to be protected by law, there must be a proper boundaries, we should avoid the interests of the copyright owner without restriction of expansion, and even violations of the rights of others.

\section{Legal Protection of Management Information}

The openness of the Internet makes it possible to use simple ways to access and use the Internet. Ordinary people on the Internet in any one of the acts, the impact and the celebrities are not different. The large amount of information and the characteristics of the Internet and the non processing and the characteristics of the Internet, which requires us to consider the legal issues related to the Internet, should be closely combined with the characteristics of the internet. Network flow works such as the stars of heaven and innumerable, and combined with digital technology characteristics, making human rights to claim their rights or others wishes to obtain a license, the first encountered the difficulty is how to identify the right people, how to find the right person. And rights management information can effectively solve this problem. As a part of human rights, information rights management is to establish a plaque, indicating the role, others shall not be altered arbitrarily, removal. But as the technical protection measures, rights management information has become the object of people with ulterior motives, or hackers to attack, is often cancel and change. This is the right people do not want to see, they also want the law to protect the rights of the right management information. It is worth noting that the technical measures and rights management information is mainly used to protect the rights of people, but due to technical measures to make others cannot distort, tamper with the work, to protect the integrity of the work, the right management information to label the name of the right people, objectively also played a role in protecting the rights of the author.

\section{Measures to Improve Legal Protection of Copyright in the Internet}

\section{Strength Law Protection}

One of the important issues in the protection of network copyright is the lack of standardized network publishing activities. It seriously affects the development of network publishing to the healthy and orderly and healthy direction. In addition to the establishment of network copyright protection laws and regulations, the author considers the following three aspects of the two levels to improve our country's information network of the legal system, so that these regulations better convergence. In terms of content, one is comprehensive, such as communication and information services, electronic commerce, electronic intellectual property, etc., two is information content, such as information collection and processing, Internet access and services, electronic publishing and network news, etc., three is information network security, information network security, digital 
signature and certification, etc.. In form, one is the law, such as information law, communications law, electronic commerce law, etc., two are administrative regulations, such as Internet, Internet information service management approach, Internet security regulations, information collection and processing regulations. Improve the level of network publishing regulations. China is currently not a specialized network regulations, the existing relevant laws and regulations, only a number of administrative measures, and some only the rules and regulations, has been difficult to adapt to the needs of the development of the network, the need to increase the law to the law's height is an urgent need to be urgent. We should pay attention to the construction of the non operating websites' supervision and regulations.

\section{Enhance Judicial Protection}

At present, domestic and foreign intellectual property circles generally believe that the development of digital technologyt is only a new way to create and spread all kinds of production, which cannot shake the foundation of the copyright system, and will not lead to the elimination of the copyright system and the reconstruction of the basic theory. The basic principle, the basic principle and the basic system of the current civil law, the copyright law and the civil procedure law are the basic rules to adjust the legal relation of the network copyright. Whether it is the use of digital technology or in the network environment to spread information, will be involved in the use of the work, so it is necessary to involve the user and the copyright owner of the rights and obligations of the basic civil relationship. Therefore, copyright law is still a legal basis for the court to try new technology, the general rules of civil law; the tort liability system is the legal basis for judging the copyright infringement. When the specific use of legal norms grasp the characteristics of the network technology, the technical characteristics and the combination of the law, the right to use the law. Copyright law is a law which is closely related to science and technology, and copyright disputes are often professional and technical. Therefore, in the network copyright litigation, we must grasp the technical characteristics to judge the parties of civil action and litigation to guide the correct use of the principle of law and regulations.

\section{OptimizeAdministrative Protection}

The administrative protection of the network copyright is to protect the legitimate rights and interests of the parties. As one of the important ways to spread the work, the Internet has been used to carry out the work of the works. However, this judicial interpretation only provides for the adaptation of the online copyright cases, and cannot protect the rights of the copyright owner in a wider range. At present, there are a lot of blind spots in our country on the Internet copyright law, the traditional method of copyright protection cannot be fully applied to the network. China's information network transmission right is the right of copyright owner's right of information network transmission right, that is to provide the public with cable or wireless way, so that the public can obtain the right of work in the time and place of his personal choice, but there is no corresponding protection measures, the rights and obligations of the relevant subjects in the copyright protection is not clear, it is difficult to adapt to the needs of administrative law enforcement. As China's first real Internet content copyright protection laws and regulations, the development of this law will have an important and far-reaching impact on the development of the Internet industry and the entire information service industry. In fact, the copyright protection of the administrative protection has the advantages of the transfer, the efficiency priority and the cost of the small, fast speed, can quickly restore the rights of the parties. Administrative protection is generally active protection, administrative protection of the compensation for infringement can be the first mediation, mediation cannot be resolved, for the rights of people to maintain their own interests more provides a way; the advantages of administrative protection is just right to make up for the defects of judicial protection, the combination of the two can be more comprehensive protection of the interests of the people. After the authorization of the copyright owner, the copyright collective management organization may, in its own name, claim the right of the copyright owner and the copyright holder, and may act as a party to a lawsuit or arbitration relating to copyright or copyright. In this way, the site will be able to work with the copyright related 
matters to the organization for the agency, not only to save a certain time and energy to avoid many unnecessary legal disputes.

\section{Conclusion}

Copyright law applies to the network environmentnaturally, but it's necessary to strength the legal protection under the internet environment. The theory of interest balance is the foundation of copyright law, and the principle of the copyright law must follow. Under the network environment, the interests of the copyright owner are easier to lose control. Therefore, it is necessary to reaffirm and clarify the rights of the copyright owner. At the same time, according to the characteristics of digital technology, the copyright protection of the rights management information and technical protection measures must be referred to the amendments to the copyright law. As the network technology a dynamic and evolvingtechnology, the problem of copyright protection under the network environment is endless. Thelegal issue of copyright protection in the internetneeds further explored.

\section{References}

[1] Liu Jian, Research on Issue of the Protection of the Copyright in the Internet, D. Hebei University, 2009.

[2] WanKan, The Discussion on the Copyright Protectionunder the Background of Internet, J., Sci-Tech Information Development \& Economy, 22(2012)108-109.

[3]Lu Kai, Liu Fei, Strict Protection of Copyright on the Internet, J.,Journal of Tianjin University (Social Sciences), 1(2014)51-56.

[4]Lu Kai, Liu Fei, Wang Shuen, AStatus Analysisand Countermeasure StudyontheInternet Copyright ProtectionofChina, J., Scientific Management Research, 3(2013)13-15. 